\title{
THE ROLE OF NASOLACRIMAL INTUBATION IN THE MANAGEMENT OF CHILDHOOD EPIPHORA
}

\author{
R. K. AGGARWAL ${ }^{1}$, G. P. MISSON ${ }^{1}$, I. DONALDSON ${ }^{2}$ and H. E. WILLSHAW ${ }^{3}$ \\ Birmingham
}

\begin{abstract}
SUMMARY
Nasolacrimal intubation has been advocated to obviate the need for dacryocystorhinostomy (DCR) for childhood epiphora which fails to resolve despite apparently successful probings. Twenty-eight intubations were attempted on children falling into this category. Of these, 25 were anatomically successful intubations ( 3 having had to be abandoned because of difficulties in retrieving the silicone tubes from the nose). Twenty patients ( $80 \%)$ had complete resolution of symptoms, $2(8 \%)$ had improvement of symptoms such that no further intervention was necessary and $3(12 \%)$ proceeded to DCR. A greater likelihood of a good outcome was seen if the tubes were left in situ for 6 months or more. We suggest that primary nasolacrimal intubation (that is nasolacrimal intubation without DCR) should be the next step in the management of childhood epiphora which fails to resolve after two probings. This approach may avoid a DCR in over $80 \%$ of children.
\end{abstract}

Epiphora affects approximately $20 \%$ of all neonates, with spontaneous resolution being the rule and occurring in $96 \%$ of cases within 12 months. ${ }^{1}$ In view of this natural history, intervention is rarely required before 12 months of age. For unresolved epiphora, probing is a very successful procedure. ${ }^{2}$ In a small minority of children, despite apparently successful probing, persistent epiphora requires more aggressive management.

Nasolacrimal intubation with silicone tubes has been advocated to avoid the need for dacryocystorhinostomy (DCR). ${ }^{2-4}$ We report our experience with 28 consecutive attempted nasolacrimal intubations.

\section{PATIENTS AND METHODS}

During the 5 year period January 1987 to December 1991, 19 patients were admitted for nasolacrimal intubation ( 9 bilateral and 10 unilateral), a total of 28 procedures. A

From: ${ }^{1}$ Birmingham and Midland Eye Hospital, Birmingham; ${ }^{2}$ Selly Oak Hospital, Birmingham; ${ }^{3}$ Children's Hospital (Birmingham), Birmingham, UK.

Correspondence to: R. K. Aggarwal, Birmingham and Midland Eye Hospital, Church Street, Birmingham B3 2NS, UK. clinical diagnosis of congenital nasolacrimal duct obstruction was made in all patients on the basis of typical epiphora and recurrent or persistent discharge. Children with obvious mid-facial structural abnormalities were not included in this study. All patients had undergone at least two nasolacrimal probings which failed to resolve their symptoms: 8 had undergone two probings at another centre and one further probing was carried out in Birmingham, while 20 had undergone two probings at our centre.

All nasolacrimal intubations were performed with the patient under general anaesthesia and with endotracheal intubation. In the majority of cases (22/28) an ENT surgeon was present in theatre. Of the 28 attempted intubation procedures, 3 were abandoned because of difficulties in retrieving the silicone tubes from the nose. It is interesting to note that failure in retrieving the tubes did not occur in any case when an ENT surgeon was present (22/22).

\section{Intubation Technique}

Following induction of anaesthesia, a cotton wool applicator soaked in $4 \%$ cocaine was placed in the nose adjacent to the inferior turbinate. After 5 minutes the applicator was removed and the inferior turbinate bone fractured using a Hills elevator. The upper and lower puncta were dilated and the lacrimal system probed using a ' 0 ' or ' 00 ' gauge Bowman probe. Following successful probing the 'Concept' tubing was introduced through each punctum in turn and retrieved from the nose, by direct visualisation where possible. The tubes were then tied together and sutured to the nasal mucosa with a 5-0 Ethibond suture. It is important that tension in the tubes is sufficient to prevent prolapse of the tubing across the eye yet is lax enough to avoid cheese-wiring of the puncta. ${ }^{5}$ The inferior turbinate was then repositioned. The approximate surgical time was 10 minutes per intubation. The children were discharged following recovery from anaesthesia, and in no case was a child detained overnight.

\section{Technique for Removal of Tubes}

In the majority of cases the tubes are removed without the 
Table I. Relationship between intubation time and final outcome

\begin{tabular}{lccc}
\hline $\begin{array}{l}\text { Intubation time } \\
\text { (months) }\end{array}$ & No. in group & No. of successes & No. failed \\
\hline$<3$ & 6 & $3(50 \%)$ & $3(50 \%)$ \\
$3-6$ & 10 & $8(80 \%)$ & $2(20 \%)$ \\
$6-12$ & 9 & $9(100 \%)$ & 0 \\
\hline
\end{tabular}

This table illustrates the trend of an improving success rate when the tubes are left in situ for a longer period of time.

need for a general anaesthetic; however, in a few cases a short general anaesthetic may be necessary.

The child is reassured and laid horizontally either on a couch or a parent's knees. The tubes are located in the nose where they were sutured to the mucosa. The loop of the tube is cut between the two puncta at the medial canthus. The tubes are then withdrawn from the nose using forceps and cut free from the nasal mucosa.

\section{RESULTS}

The median age of our 19 patients was 44 months (range 11-108 months), with a median follow-up time of 6 months (range 2-16 months).

Of a total 28 attempted intubation procedures in 19 patients, 25 were successfully completed (89\%). All 3 failed intubations coincided with the absence of an ENT surgeon. Three patients (12\%) required a second short general anaesthetic to allow removal of the tubes. Of the 25 patients with successful intubations, $20(80 \%)$ had complete resolution of symptoms, 2 (8\%) had improvement of symptoms such that no further treatment was necessary and $3(12 \%)$ proceeded to DCR.

The time for which the tubes remained in place (at the last intubation for those undergoing more than one intubation) varied from 1 week to 8 months (mean 4.35 months, median 4.5 months). In 6 of the 25 successful intubations the tubes were spontaneously lost (i.e. the tubes were not in position, having fallen out either as a result of the knot coming undone or the tubes breaking) within 2 weeks of insertion. Of these 6 , complete resolution of symptoms without the need for any further intervention occurred in 2 cases; in 2 cases re-intubation led to a favourable final outcome; in the final 2 cases epiphora persisted. For tubes left in situ for less than 3 months the success rate was $50 \%$ (2/4 cases), improving to $100 \%$ (7/7) when tubes were left in situ for over 6 months. Although the numbers are too small for statistical analysis, our results suggest a relationship between the time the tubes are left in situ and a successful final outcome (Table I). This trend remains unchanged after allowance is made for the bilateral cases (random selection of one eye from the bilateral cases).

The age at intubation varied from 11 months to 9 years (mean 43 months, median 44 months). There is no clear association between outcome and age at intubation (Table II).

\section{DISCUSSION}

Management of the child with persistent symptoms despite apparently successful nasolacrimal probing is difficult. Some consider DCR in childhood to be less successful than in adult life, ${ }^{6}$ and therefore a less invasive procedure which is successful in the majority of these cases would be advantageous. We believe that all the cases in this study would have undergone DCR if intubation had not been a therapeutic option.

Intubation of the lacrimal system was first described in 1968 by Keith ${ }^{4}$ and in 1970 by Quickert and Dryden. ${ }^{7}$ Numerous subsequent studies from North America have described the technique, initially using polyethylene tubing, ${ }^{8,9}$ and later silicone tubing., ${ }^{3,5-12}$ Silicone has the advantage in that it is softer and has led to fewer complications.

In their large series of 192 eyes, Welsh and Katowitz ${ }^{13}$ showed an $83.3 \%$ success rate in patients undergoing silicone tube intubation after unsuccessful probing. Their results suggest a greater likelihood of a good outcome if the silicone tubes were left in situ for 6 months or more. Their results also support the widely held view that older patients (more than 2 years) do less well than their younger counterparts. In the older group the success rate was considerably improved from $50 \%$ when tubes were left in place for less than 3 months to over $80 \%$ if the tubes were left in place for longer than 6 months. Dortzbach et $a l .{ }^{3}$ in their study of 63 intubations report similar results with an $82.5 \%$ success rate. They advise leaving the tubes in situ for at least 4 months. Durso et al. ${ }^{6}$ reported a suc' cess rate of $84 \%$ with a mean intubation time of 3.2 months. Leone and Van Gemert ${ }^{10}$ in their series of 100 patients combined silicone tube intubation with fracturing of the inferior turbinate. Their overall success rate was higher at $97 \%$, and reached $99 \%$ for the sub-group in which the tubes were left in place for more than 6 months. All their failures were in patients over the age of 2 years. The difficulty encountered in nasolacrimal intubation is the accurate location and retrieval of the silicone tubing from the inferior meatus with minimal trauma to the nasal mucosa. This is best achieved with expert ENT assistance, as 'blind' grasping of the tubes may be unacceptably traumatic. Replacement of the inferior turbinate upon completion helps to restore normal nasal anatomy.

Such a technique not only minimises nasal trauma but may also increase the likelihood of a successful outcome. ${ }^{14}$ Our results, the first reported from the United Kingdom, are comparable to previous studies ${ }^{3,6,10,13}$ and, like previous reports, suggest a better outcome with retention of the tubes beyond 6 months. ${ }^{2}$ Our success rate improved from $50 \%$ when tubes were left in place for less than 3 months to $100 \%$ when the tubes were left in place

Table II. Variation in success rate with patient age at intubation

\begin{tabular}{lccc}
\hline $\begin{array}{l}\text { Age at intubation } \\
\text { (months) }\end{array}$ & $\begin{array}{c}\text { No. of } \\
\text { intubations }\end{array}$ & $\begin{array}{c}\text { Successful } \\
\text { intubations }\end{array}$ & $\begin{array}{c}\text { Failed } \\
\text { intubations }\end{array}$ \\
\hline$<12$ & 1 & $1(100 \%)$ & 0 \\
$12-23$ & 4 & $3(75 \%)$ & $1(25 \%)$ \\
$24-27$ & 11 & $8(73 \%)$ & $3(27 \%)$ \\
$48-71$ & 4 & $4(100 \%)$ & 0 \\
$>71$ & 5 & $4(80 \%)$ & $1(20 \%)$ \\
\hline
\end{tabular}


for at least 6 months; however, our numbers are too small for detailed statistical analysis.

The success of this procedure may involve a combination of three possible mechanisms: (1) the effect of a repeat probing; (2) infracture of the inferior turbinate (a large paediatric series ${ }^{14}$ is reported where infracturing of the inferior turbinate alone resulted in success in a high proportion of children); (3) the presence of the tubes in the nasolacrimal passage preventing recurrence of the obstruction. We think that intubation combined with inferior turbinate infracture holds the greatest potential for success without proceeding to DCR.

\section{CONCLUSION}

This is the first report describing the results of silicone tube intubation for childhood epiphora after persistent symptoms following probing in a UK population. Our success rates compare favourably with those reported from the United States. We would suggest that this procedure be considered as the next step in the treatment of children with epiphora that fails to resolve following two nasolacrimal probings. This approach may avoid a dacryocystorhinostomy in over $80 \%$ of children.

Key words: Childhood epihora, Nasolacrimal intubation, Silicone tubing.

\section{REFERENCES}

1. Macewen CJ, Yound JDH. Epiphora during the first year of life. Eye 1991;5:596-600.

2. Kushner BJ. Congenital nasolacrimal system obstruction. Arch Ophthalmol 1982;100:597-600.
3. Dortzbach RK, France TD, Kushner BJ, Gonnering RS. Silicone intubation for obstruction of the nasolacrimal duct in children. Am J Ophthalmol 1982;94:585-90.

4. Keith CG. Intubation of the lacrimal passages. Am J Ophthalmol 1968;65:70-4.

5. Anderson RL, Edwards JJ. Indications, complications and results with silicone stents. Ophthalmology 1979;86: 1474-87.

6. Durso F, Hand SI Jr, Ellis FD, Halveston EM. Silicone intubation in children with nasolacrimal obstruction. J Pediatr Ophthalmol Strabismus 1980;17:389-93.

7. Quickert MH, Dryden RM. Probes for intubation in lacrimal drainage. Trans Am Acad Ophthalmol Otolaryngol 1970;74: 431-3.

8. Werb A. The role of polyethylene tubing in lacrimal obstructions. In: Smith B, Converse JM, editors. Plastic and reconstructive surgery of the eye and adnexa. St Louis: CV Mosby, 1967:157-70.

9. Huggart A. The treatment of stenosis of the lacrimal canaliculi. Acta Ophthalmol (Copenh) 1959;37:355-8.

10. Leone CR Jr, Van Gemert JV. The success rate of silicone intubation in congenital lacrimal obstruction. Ophthalmic Surg 1990;21:90-2.

11. Katowitz JA. Silicone tubing in canalicular obstructions. Arch Ophthalmol 1974;91:459-62.

12. Migliori ME, Putterman AM. Silicone intubation for the treatment of congenital lacrimal duct obstruction: successful results removing the tubes after six weeks. Ophthalmology 1988;95:792-5.

13. Welsh MG, Katowitz JA. Timing of silastic tubing removal after intubation for congenital nasolacrimal duct obstruction. Ophthalmic Plast Reconstr Surg 1989;5:43-7.

14. Wesley RE. Inferior turbinate fracture in the treatment of congenital nasolacrimal duct obstruction and.congenital nasolacrimal duct anomaly. Ophthalmic Surg 1985;16: $368-71$. 